cues to judge competence, such as how the doctor questions them, communicates about their illness, and answers questions. Some patients judge competencesometimes incorrectly-by the course of their illness and their responses to treatment. Central to patients' trust is how doctors communicate and whether they listen and are caring. Patients do not expect intimacy but they do seek respect and responsiveness. The kinds of communication skills patients value are teachable skills. Finally, patients want to know that their doctors are committed to protecting their interests. Patients in varying contexts may be more or less aware and willing to accept that their doctors are allocators as well as givers of care, but they must feel that their doctors are on their side. The availability of choice reinforces trust in the doctor as agent. ${ }^{8}$

We still know little empirically about the transfer of trust between personal doctors and managers, consultants, hospitals, and the larger health system. Doctors are the gateway to organisational trust. Health plans in the United States elicit trust through the qualifications and reputations of affiliated doctors. Whether the failures of these larger organisations diminish their doctors as well is less clear. In instances where the organisation is held in high public regard, as is the case with the Harvard Medical School, Johns Hopkins Medical School, and the Mayo Clinic, affiliated doctors may also gain in reputation. Doctors and managers stand to benefit by collaborating in building trust in clinicians and in larger systems.

Most patients view medical care in terms of the personal doctor-patient relationship and are not sophisticated about organisational structures and strategies, such as managed care, and how they work. But they want their own doctors, not managers, to control their medical care. This creates a dilemma for managers seeking to reduce variations in care, eliminate inefficiencies, and introduce evidence based standards of care. Managers have to tread carefully, sensitive to the importance of the doctor-patient alliance and the value of trust on which it is often based.

Patients may trust blindly when some scepticism is warranted. Much care that is needed is never provided, and ineffective and inappropriate care is common. ${ }^{9}$ As more information is available for patients in the media and on the internet they often encounter conflicting advice. Patients have many questions about their care and, in the United States, advertising of pharmaceuticals and medical treatments directly to the consumer leads to even more questions. ${ }^{10}$ Few primary care doctors have the time to respond adequately and to make the patient a true partner in care.

Health administrators and managers attempt to deal with such challenges by providing accessible and reliable information to patients, by putting in place disease management programmes that make effective use of nurses and other health professionals, and work with doctors to help them improve their practices. ${ }^{11}$ Electronic information systems offer opportunities to improve communication, avoid errors, and help patients become proactive in their own care. ${ }^{12}$ Managerial interventions carelessly introduced can diminish trust among both health professionals and patients. But if pursued collaboratively they offer potential to promote quality and trust and contribute to satisfaction of both patients and clinicians.

\section{David Mechanic director}

Rutgers, State University of New Jersey Institute for Health, Health Care Policy and Aging Research, 30 College Avenue, New Brunswick, NJ 08901, USA

(mechanic@rci.rutgers.edu)

\section{Competing interests: None declared.}

Misztal BA. Trust in modern societies: the search for the bases of social order Cambridge, MA: Polity Press, 1996.

Nye JS Jr, Zelikow PD, King DC, eds. Why people don't trust government. Cambridge, MA: Harvard University Press, 1997.

3 Focus: News from Harvard Medical, Dental, and Public Health Schools. Initiative looks for ways to build trust. 24 January 2003. http:// focus.hms.harvard.edu/2003/Jan24_2003/research_briefs.html focus.hms.harvard.edu/
(accessed 16 Sep 2004)

4 Jacobs LR, Shapiro RY. Politicians don't pander: political manipulation and the loss of democratic responsiveness. Chicago, London: University of Chicago Press, 2000:237-40.

5 Mechanic D. The functions and limitations of trust in the provision of medical care. J Health Polit Policy Law 1998;23:661-86.

6 The Kaiser Family Foundation, Agency for Healthcare Research and Quality. National survey on Americans as health care consumers: an update on the role of quality information. December 2000. www.kff.org/kaiserpolls loader.cfm? url = $/$ commonspot/security $/$ getfile $c$ fm\&.PageID $=13573$ (accessed 20 Sep 2004).

7 Mechanic D, Meyer S. Concepts of trust among patients with serious illness. Soc Sci Med 2000;51:657-68.

Schmittdiel J, Selby JV, Grumbach K, Quesenberry CP Jr. Choice of a personal physician and patient satisfaction in a health maintenance organization. JAMA 1997;278:1596-9.

9 McGlynn EA, Asch SM, Adams J, Keesey J, Hicks J, DeCristofaro A, et al. The quality of health care delivered to adults in the United States. N Eng J Med 2003;348:2635-45.

10 Mechanic D. Physician discontent: challenges and opportunities. JAMA 2003;290:941-6.

11 Halvorson GC, Isham GJ. Epidemic of care: a call for safer, better, and more accountable health care. San Francisco: Jossey-Bass, 2003.

12 Millenson ML Demanding medical excellence.doctors and accountability in the information age. Chicago: University of Chicago Press, 1997.

\title{
Lifting the fog of uncertainty from the practice of medicine
}

\author{
Strategy revolves around evidence, decision making, and leadership
}

$\mathrm{D}$ espite the exponential growth of medical information, the effects of healthcare interventions are often uncertain or controversial. ${ }^{\mathrm{w} 1}$ This unreliability or uncertainty of all information is what the military philosopher Clausewitz called the fog of war. ${ }^{1}$ Clausewitz maintained that the key to a rational approach to warfare was understanding the impact of chance and the laws of the probability and its interplay with the other factors in war-such as people, governments, and, in particular, the commander in the field. This approach may also benefit health care.

Recently, McNeil argued that the major hidden barriers to better health care result from a lack of discussion of the impact of uncertainty in medicine. ${ }^{2}$ She enumerated several sources of uncertainty that cloud

Additional references w1-w8 are on bmj.com 
decision making in modern health care: uncertainty as a result of lack of convincing evidence because of delayed or obsolete data from clinical studies; uncertainty about applicability of evidence from research at the bedside; and uncertainty about interpretation of data. ${ }^{2}$ w2 Others have noted that failure to learn how to make decisions under uncertainty is the leading cause of excessive diagnostic testing and inappropriate treatments. ${ }^{\text {w3 }}$

Can the fog that enshrouds the medical practice be lifted? The strategy for this revolves around evidence, decision making, and leadership.

\section{Identifying relevant evidence}

Most existing evidence is irrelevant or unreliable. Research in medicine indicates that using filters to identify relevant and valid evidence can reduce the background noise by $99.96 \%$, resulting in only five to 50 research articles per year that may need to be incorporated in systematic reviews. ${ }^{3}$ In oncology, less than $1 \%$ of new evidence has been judged to be important for practising doctors. ${ }^{4}$ Therefore, it is an achievable goal to identify relevant and valid evidence which can be delivered when needed at the point of care ideally in its totality as a systematic review. ${ }^{\mathrm{w4}} \mathrm{w5}$

\section{Improving connectivity between data, information,} and knowledge

Many avoidable shortcomings in health care occur because evidence is inaccessible at the time and place it is needed. ${ }^{5}$ If evidence was provided when needed the decisions could have been different $30-60 \%$ of times. ${ }^{4}$ Here again a lesson from the military is relevant to medicine: investment in the infrastructure for information and communication to improve connectivity between users enabling management of data, information, and knowledge will go a long way in lifting the fog from the practice of medicine. ${ }^{5}$

\section{Training doctors for decision making under uncertainty}

Although reliable evidence is the backbone of effective decision making, too often evidence is confused with decision making. ${ }^{6}{ }^{\text {w }}$ Evidence is expressed on a continuum scale of credibility, whereas decision making is about choice and is a categorical exercise-we decide or do not. ${ }^{6}$ Rationality of choice is a matter of choosing, not of what is chosen-that is, a good decision can result in bad outcomes and a bad one in good outcomes. ${ }^{7}$ Normative theories of decision making hold that rational decision making is the one that maximises the value of consequences on the basis of the probabilities of consequences and the values associated with each consequence of a choice. Although formal decision models and other prescriptive aids will have an increasing role in integration of evidence within theoretic decision frameworks, ${ }^{8}$ some friction or uncertainty at the point of care will probably always remain. Similarly to modern descriptive decision theories which noticed that people often violate normative precepts, Clausewitz also noted that theory and experience often clash. ${ }^{1}$ Here he believed that action should remain in the hands of the capable commander in the field whose creativity, talent, and genius will be able to guide his troops through the fog of the battle. Likewise, decisions for individual patients will always remain with skilful doctors able to navigate successfully through the sea of uncertainty of clinical practice. However, the current generation of doctors is not well trained to deal with clinical uncertainty. The failure to train doctors about clinical uncertainty has been called "the greatest deficiency of medical education throughout the twentieth century."' The new generations of doctors need to be properly trained to face inherent uncertainty in clinical encounters.

\section{Bold leadership is needed to inform the public about uncertainties}

None of the above will happen until our leaders and the public understand the inherent limitations of medical knowledge and the role of research in reducing uncertainty. ${ }^{\mathrm{w} 6}$ The increasing gap between the research agenda and the needs of patients and practitioners will not decrease until leaders are ready to tell the public what knowledge exists to guide management by practitioners. ${ }^{w / 7}$ Adopting business models in medicine seems to have led current leaders in medicine to value perception over substance, marketing over open discourse. Only when the public finally grasps how little reliable knowledge exists will it have the motivation to become actively involved in prioritising the research agenda. Ultimately improvement in clinical care and patients' outcomes will come from conducting the right kind of research, research that is of importance in the real world, as advocated in the recently established James Lind Alliance. ${ }^{w 8}$ Acknowledging uncertainties and informing patients about them is a key strategy for improving health care and lifting the fog from the practice of medicine. ${ }^{10} 11$

\section{Benjamin Djulbegovic professor of oncology and medicine}

H Lee Moffitt Cancer Center and Research Institute, University of South Florida, Department of Interdisciplinary Oncology, 12902 Magnolia Drive, Tampa, FL 33612, USA

(djulbebm@moffitt.usf.edu)

Competing interests: None declared.

1 Von Clausewitz C. On war. Princeton, NJ: Princeton University Press, 1976.

2 McNeil BJ. Hidden barriers to improvement in the quality of care. $N$ Engl J Med 2001;345:1612-20.

3 Haynes B. Bridging the gap between the Cochrane Collaboration and clinical practice. Plenary presentation. 12th Cochrane Colloquium, Ottawa, 3 October 2004.

4 Djulbegovic B, Coleman R, Stahel R, Singh D, Lyman G. Evidence-based oncology in cancer treatment reviews a. Cancer Treat Rev 2003;29:45-50.

5 Detmer DE. Building national health information structure for personal health, health care services, public health, and research. BMC Med Informatics Decision Making 2003;3:1. www.biomedcentral.com/14726947/3/1 (accessed 1 Dec 2004).

6 Djulbegovic B. Evidence and decision-making. J Eval Clin Practice 2005 (in press).

7 Hastie R, Dawes RM. Rational choice in an uncertain world. London: Sage, 2001.

8 Djulbegovic B, Hozo I, Lyman G. Linking evidence-based medicine therapeutic summary measures to clinical decision analysis. MedGenMed 2000 (January 13) www.medscape.com/Medscape/GeneralMedicine/ journal/2000/v02.n01/mgm0113.djul/mgm0113.djul-01.html (accessed 8 Dec 2004)

9 Ludmerer KM. Time to heal. New York: Oxford University Press, 1999.

10 Chalmers I. Well informed uncertainties about the effects of treatments. BMJ 2004;328:475-6.

11 Djulbegovic B. Acknowledgment of uncertainty: a fundamental means to ensure scientific and ethical validity in clinical research. Curr Oncol Rep 2001;3:389-95. 